Atmos. Chem. Phys., 13, 11287-11293, 2013

www.atmos-chem-phys.net/13/11287/2013/

doi:10.5194/acp-13-11287-2013

(c) Author(s) 2013. CC Attribution 3.0 License.

\title{
Method development estimating ambient oxidized mercury concentration from monitored mercury wet deposition
}

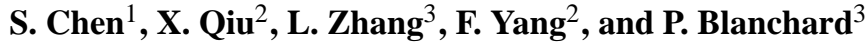 \\ ${ }^{1}$ Department of Mathematics and Statistics, York University, Toronto, Canada \\ ${ }^{2}$ Novus Environmental Inc., Guelph, Canada \\ ${ }^{3}$ Air Quality Research Division, Science and Technology Branch, Environment Canada, Toronto, Canada
}

Correspondence to: L. Zhang (leiming.zhang@ec.gc.ca)

Received: 9 April 2013 - Published in Atmos. Chem. Phys. Discuss.: 14 May 2013

Revised: 13 October 2013 - Accepted: 23 October 2013 - Published: 21 November 2013

\begin{abstract}
To quantify mercury dry deposition, the Atmospheric Mercury Network (AMNet) of the National Atmospheric Deposition Program (NADP) was established recently to monitor the speciated atmospheric mercury (i.e. gaseous elemental mercury (GEM), gaseous oxidized mercury (GOM) and particulate-bound mercury (PBM)). However, the spatial coverage of AMNet is far less than the long-established Mercury Deposition Network (MDN) for wet deposition monitoring. The present study describes the first attempt linking ambient concentration of the oxidized mercury $(\mathrm{GOM}+\mathrm{PBM})$ with wet deposition aiming to estimate $\mathrm{GOM}+\mathrm{PBM}$ roughly at locations and/or times where such measurement is not available but where wet deposition is monitored. The beta distribution function is used to describe the distribution of GOM + PBM and is used to predict GOM + PBM from monitored wet deposition. The mean, median, mode, standard deviation, and skewness of the fitted beta distribution parameters were generated using data collected in 2009 at multiple monitoring superstations. The established beta distribution function from the 2009 GOM + PBM data is used to construct a model that predicts GOM + PBM from wet deposition data. The model is validated using 2010 data at multiple stations, and the predicted monthly GOM + PBM concentrations agree reasonably well with measurements. The model has many potential applications after further improvements and validation using different data sets.
\end{abstract}

\section{Introduction}

Atmospheric mercury $(\mathrm{Hg})$ is operationally defined as gaseous elemental $\mathrm{Hg}$ (GEM), gaseous oxidized $\mathrm{Hg}(\mathrm{GOM})$, and particulate-bound $\mathrm{Hg}(\mathrm{PBM})$. Such a classification practice has been used in field data collections as well as in $\mathrm{Hg}$ transport models simulations. Speciated atmospheric $\mathrm{Hg}$ data are useful in studies on various topics, for example, identifying $\mathrm{Hg}$ source-receptor relationships (Lynam et al., 2006; Swartzendruber et al., 2006; Choi et al., 2008; Rutter et al., 2009; Weiss-Penzias et al., 2009; Huang et al., 2010; Sprovieri et al., 2010; Cheng et al., 2012, 2013), understanding $\mathrm{Hg}$ cycling and partitioning (Engle et al., 2008; Steffen et al., 2008; Amos et al., 2012), evaluating $\mathrm{Hg}$ transport models (Baker and Bash, 2012; Zhang et al., 2012a), and quantifying Hg dry deposition budget (Engle et al., 2010; Lombard et al., 2011; Zhang et al., 2012b).

To enhance the estimation of $\mathrm{Hg}$ dry deposition on a regional scale in North America, a new monitoring network - the Atmospheric Mercury Network (AMNet) - was established recently within the National Atmospheric Deposition Program (NADP) (Gay et al., 2013). However, the spatial coverage of AMNet, which has around 20 monitoring sites in USA and Canada, is far less than the long-established NADP's Hg wet deposition network - the Mercury Deposition Network (MDN) - which has more than 100 monitoring sites. While most Hg transport models could produce reasonable GEM values on various spatial and temporal scales, they frequently failed to capture the magnitudes of GOM and PBM values at both urban and rural locations (Baker and Bash, 2012; Zhang et al., 2012a). 
The motivation of this study came from a recent mercury transport model evaluation study (Zhang et al., 2012a) in which the modelled surface concentrations for oxidized mercury were found to be 2-10 times higher than the monitored concentrations at multiple locations. Thus, if using modelled dry deposition or using modelled surface concentration to estimate dry deposition, the results would be biased high significantly. Considering that mercury collected in precipitation is mainly from oxidized mercury (GOM and PBM), it might be possible to generate some statistical relationships between the ambient concentration and the wet deposition. Because of the many factors (such as in-cloud and under-cloud scavenging) affecting the wet deposition, it is not realistic to expect a very simple relationship. The goal is to develop a method that might generate reasonable GOM and PBM concentrations from wet deposition over a relatively long period (e.g. monthly or longer periods). The present study aims to develop a method linking ambient GOM and PBM concentrations with $\mathrm{Hg}$ wet deposition for the above-mentioned potential application. Monitored data from AMNet for ambient GOM and PBM concentrations and MDN for wet deposition were applied to the study.

\section{Relationship between ambient concentration and wet deposition}

Mercury wet deposition $w$ measured in a collector follows a balance equation (Amos et al., 2012):

$w=F_{T P} m+F_{T P}^{\prime} l$,

$m=P V c$,

where $F_{T P}$ and $F_{T P}^{\prime}$ are fractions of mercury from ambient scavenged $m$ and from exogenous source $l$ carried by water droplets in clouds through long-range transport. Both fractions are functions of the local temperature $T$ and precipitation $P$ as specified in Appendix A. Especially, both fractions are zero when $P$ is zero. Furthermore, the scavenged $m$ is a function of the mercury ambient concentration $c$, precipitation $P$ and the under cloud air column $V$ as indicated in Eq. (2). For Eqs. (1) and (2), $c$ can be measured at an ambient monitoring station, and $w$ can be measured at a wet deposition station. However, there is considerable uncertainty regarding the atmospheric redox chemistry of $\mathrm{Hg}$ (Hynes et al., 2009), and atmospheric measurement methods are subject to artefacts (Gustin and Jaffe, 2010). Hence the above balance equation serves as a guideline (Appendix A). Clearly, it is impossible to solve Eqs. (1) and (2) for $c$ since $l$ and $V$ are unknown. Hence we are interested in a more realistic goal: improving the mean estimate of $c$ by using the wet deposition information $w$ through a statistical method. To simplify the case further, GOM and PBM are lumped together as the total of the ambient oxidized $\mathrm{Hg}$.

Data collected at AMNet and MDN collocated sites, where both wet deposition and ambient concentrations are avail- able, were selected for this study to establish the statistical regression model. The first step was to generate the distribution density functions including their fittings and input parameters for GOM + PBM concentration and wet deposition. The second step was to establish the statistical relationship between GOM + PBM concentration and wet deposition and precipitation. This model can then be used to approximately estimate GOM + PBM from wet deposition. It is noted that AMNet only collects a fine fraction of PBM $\left(\mathrm{PM}_{2.5}\right)$ while wet deposition should have included all sizes of PBM. Although a rough assumption can be made for the coarse fraction of PBM, this will further introduce more uncertainties. Because we used statistical distribution approach to estimate the relationship between the ambient and wet $\mathrm{Hg}$, we simply used the monitored GOM + PBM without the complication of the coarse PBM.

\section{Statistical model for GOM + PBM}

Statistical experiments suggest that GOM + PBM concentration (referred to as ambient concentration $c$ below) can be described as a normalized random variable $c_{0}$ using beta distribution between zero and one:

$c_{0} \sim B\left(\alpha_{c}, \beta_{c}\right), \alpha_{c}>1, \beta_{c}>1$.

Depending on different parameters of $\alpha_{c}$ and $\beta_{c}$, this unimodal beta distribution could skew left or right, and could be flat or steep, hence capable of capturing many different ambient concentration distributions.

Weekly GOM + PBM concentrations in 2009 at 11 AMNet sites were used to estimate $\alpha_{c}$ and $\beta_{c}$. These sites are MD08, NH06, MD97, NJ30, NJ32, NJ54, NY06, NY20, NY43, OH02 and VT99 and were described in Zhang et al. (2012b). By the method of moments, we obtained the estimates of $\alpha_{c}=1.28$ and $\beta_{c}=72.48$. The mean, median, mode, and standard deviation (std) of this fitted beta distribution are given in Table 1 . The normalized histogram of GOM + PBM is shown in Fig. 1 along with the fitted density function. We can see that using a beta distribution can reasonably describe the distribution of ambient concentration.

\section{Statistical model with wet deposition}

From Eq. (1) we can get $1=\frac{F_{T P} P V c}{w}+\frac{F_{T P}^{\prime} l}{w}$. Both terms on the right-hand side must be positive, and they can be interpreted as the fraction of wet deposition. Since $l$ and $V$ are unknown, we are not able to solve this equation for ambient $\mathrm{Hg}$ concentration $c$. On the other hand, because the ambient $\mathrm{Hg}$ concentration statistically fits beta distribution very well as described in the previous section, the ratio term $\frac{F_{T P} P V c}{w}$ could be statistically modelled as a random variable with beta distribution. Since $V$ is unknown, statistical fitting practice should be focused on $\frac{F_{T P} P c}{w}$, where $F_{T P}$ can be estimated 


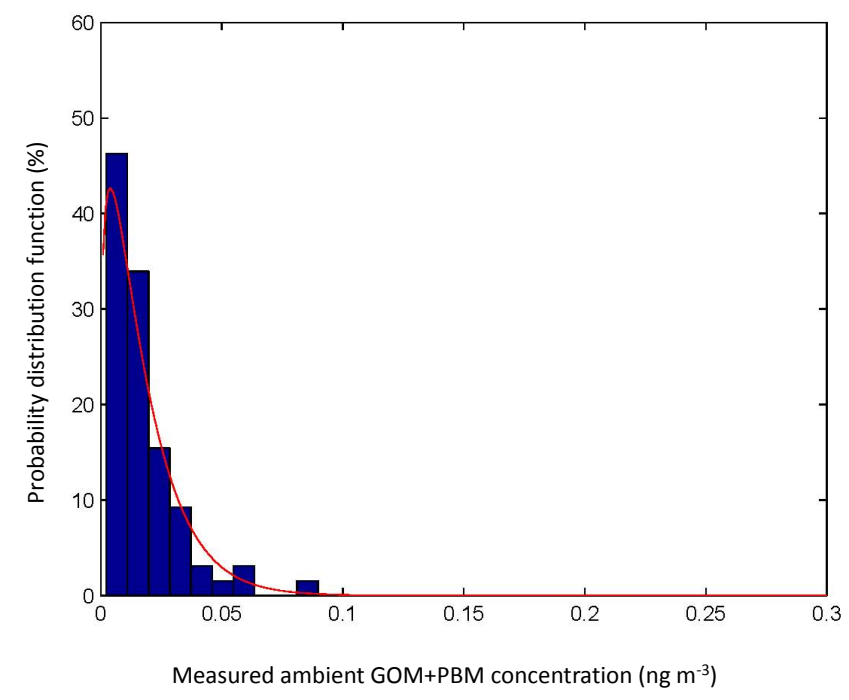

Fig. 1. Normalized histogram (blue bar chart) and fitted beta distribution (red curve) for ambient concentration (GOM + PBM).

Table 1. Fitted beta distribution of the dry ambient concentration.

\begin{tabular}{lllll}
\hline Mean & Median & Mode & Std & Skewness \\
\hline 0.0174 & 0.0133 & 0.004 & 0.0151 & 1.6848 \\
\hline
\end{tabular}

using Eq. (19) in Appendix A. By examining both $\mathrm{Hg}$ wet deposition $w$ and ambient concentration $c$ from weekly 2009 monitoring data, we observed that the total ambient dry concentration $c$ is not linear to the wet deposition $w$ and the precipitation $P$. Instead, a highly nonlinear relationship appears. With a number of fitting and experimenting practice by using 2009 weekly data from three superstations - MD08, OH02 and VT99 (where both wet deposition and dry ambient concentration were monitored) - we define a random variable in beta distribution $r$, which is a function of

$r=\frac{F_{T P} P^{a} c}{w^{b}} \sim B\left(\alpha_{r}, \beta_{r}\right)$,

where $a=1 / 3$ and $b=1 / 5$ are empirical constants based on the fitting experiment. By the method of moments, we got the following estimates for beta fitting of $r: \alpha_{r}=0.8396$ and $\beta_{r}=61.7909$. Based in the fitted $\alpha_{r}$ and $\beta_{r}$, we obtain the mean, median, mode, std, skewness of the fitted beta distribution as shown in Table 2. Figure 2 suggests that the fitted density function for the ratio $r$ is a close fit to the $r$ distribution generated from the measured data.

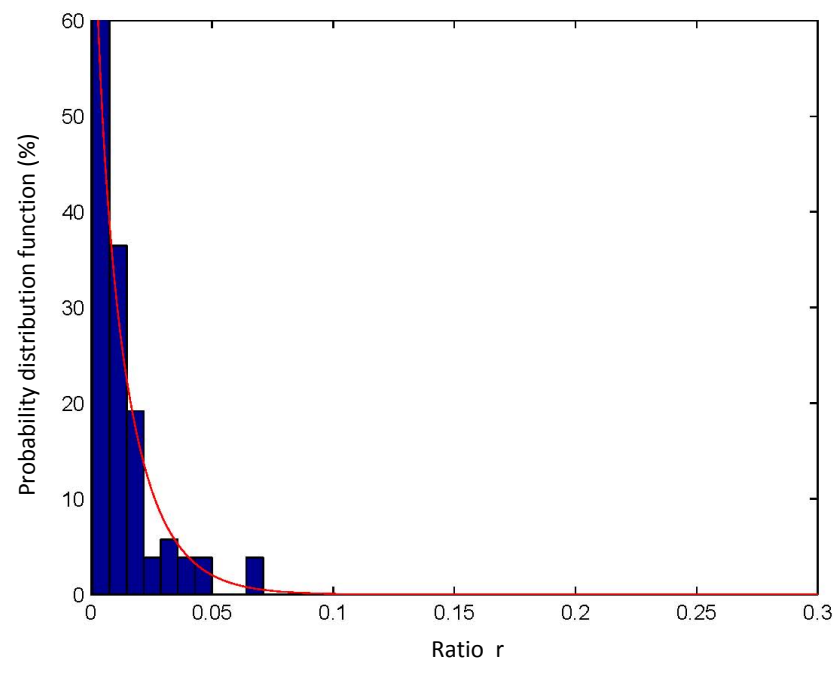

Fig. 2. Same as in Fig. 1 except for ratio $r$ defined in Eq. (4).

Table 2. Fitted beta distribution of the ratio $r$ defined in Eq. (4).

\begin{tabular}{lllll}
\hline Mean & Median & Mode & Std & Skewness \\
\hline 0.01 & 0.0079 & 0.0034 & 0.0080 & 1.5833 \\
\hline
\end{tabular}

\section{Estimate of ambient $\mathrm{Hg}$ concentration from wet deposition}

To estimate ambient $\mathrm{Hg}$ concentration $c$ from wet deposition $w$ and precipitation $P$, we can apply Eq. (4) to get

$c=\frac{\bar{r} w^{b}}{F_{T P} P^{a}}$,

where $a=1 / 3$ and $b=1 / 5$. Note that the mean value $\bar{r}=$ 0.01 is applied in the formula derived by the beta fitting experiment in Table 2. The scatter plot between observed monthly GOM + PBM from the three superstations and the corresponding estimations from Eq. (5) is shown in Fig. 3. The plot shows that most points are centred around the $1: 1$ line with a correlation coefficient of 0.43 .

To analyse errors further, we define the error as

$e=c_{\mathrm{obs}}-c_{\text {estimated }}$.

The box plot and the normality plot of the estimate error are shown in Fig. 4. We can see that the error has nearly zero mean, and is symmetric in Fig. 4a; the error distribution is approximately normal in Fig. 4b. The lower end of Fig. 4b shows a certain deviation from normal distribution, which might due to difficulty in obtaining accurate measurement of extremely small mercury concentrations. The middle part of Fig. $4 \mathrm{~b}$ also shows a near-perfect fit of normality. Figure $4 \mathrm{a}$ shows the majority of variations are in the 0.02 to 0.04 interval, and our statistical method yields approximately half higher estimates and half lower estimates, which accounts 


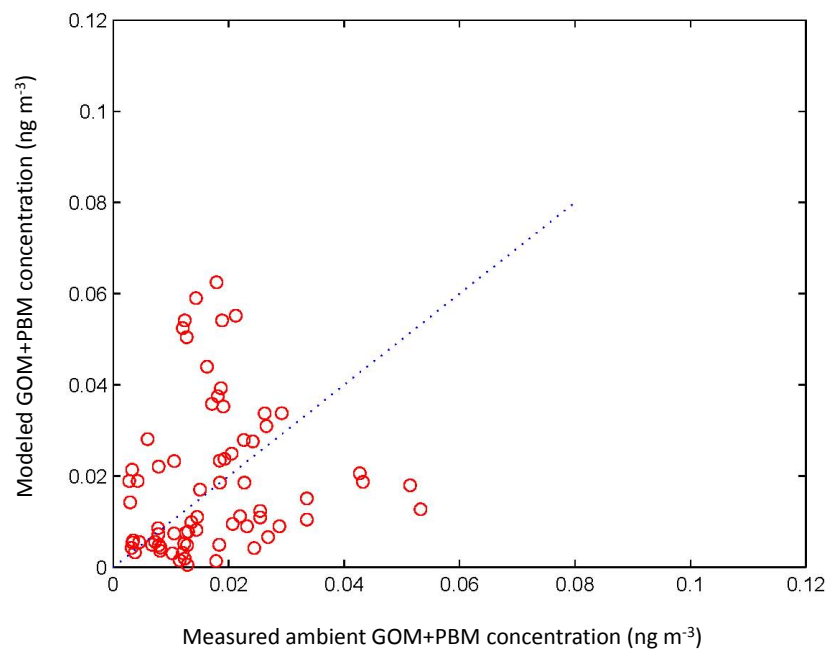

Fig. 3. Scatter plot of modelled and measured ambient GOM + PBM concentration in 2009 at three sites.

for the high variation in this region. For large concentration values, upper end of Fig. $4 \mathrm{~b}$ shows a near-perfect fit of normality. This result implies that the method is robust. Our validation using 2010 data confirms this observation.

\section{Model validations}

The purpose of this study is to develop a statistical model allowing us to use $\mathrm{Hg}$ wet deposition to estimate ambient oxidized $\mathrm{Hg}$ concentration on monthly or a longer period basis. To validate the model, data from a different year 2010 than that used for model development (2009) and at more sites were used. Monthly average $\mathrm{Hg}$ wet deposition $w$ and precipitation $P$ in 2010 at seven sites - MD08, MD99, NJ30, NY06, NY20, NY43 and OH02 - were applied to Eq. (5) to estimate monthly GOM + PBM. The mean value $\bar{r}=0.01$, $a=1 / 3$ and $b=1 / 5$ generated from 2009 data were used. The scatter plot between modelled and measured monthly concentration in 2010 at the seven stations shows a better fit than 2009 results with a correlation coefficient of $R=0.69$ (Fig. 5). The scatter plot suggests a promising estimate of ambient $\mathrm{Hg}$ concentrations by wet deposition data. Furthermore, the box plot and the normality plot of estimate error show that the error has nearly zero mean and is symmetric, which is similar but better than 2009 results (Fig. 6).

We further validate that the 2010 dry and wet $\mathrm{Hg}$ data follow the same beta distribution pattern as in 2009. On the 2010 validating data set, we use the same approach and find that beta distribution accurately describes ambient $\mathrm{Hg}$ concentration distribution as shown in Fig. 7. This confirms our choice of beta distribution as a proper statistical model for describing the ambient $\mathrm{Hg}$ concentration. Similarly, we apply the statistical model with 2010 wet deposition information that the constructed ratio estimate $r$ follows a beta distribution as
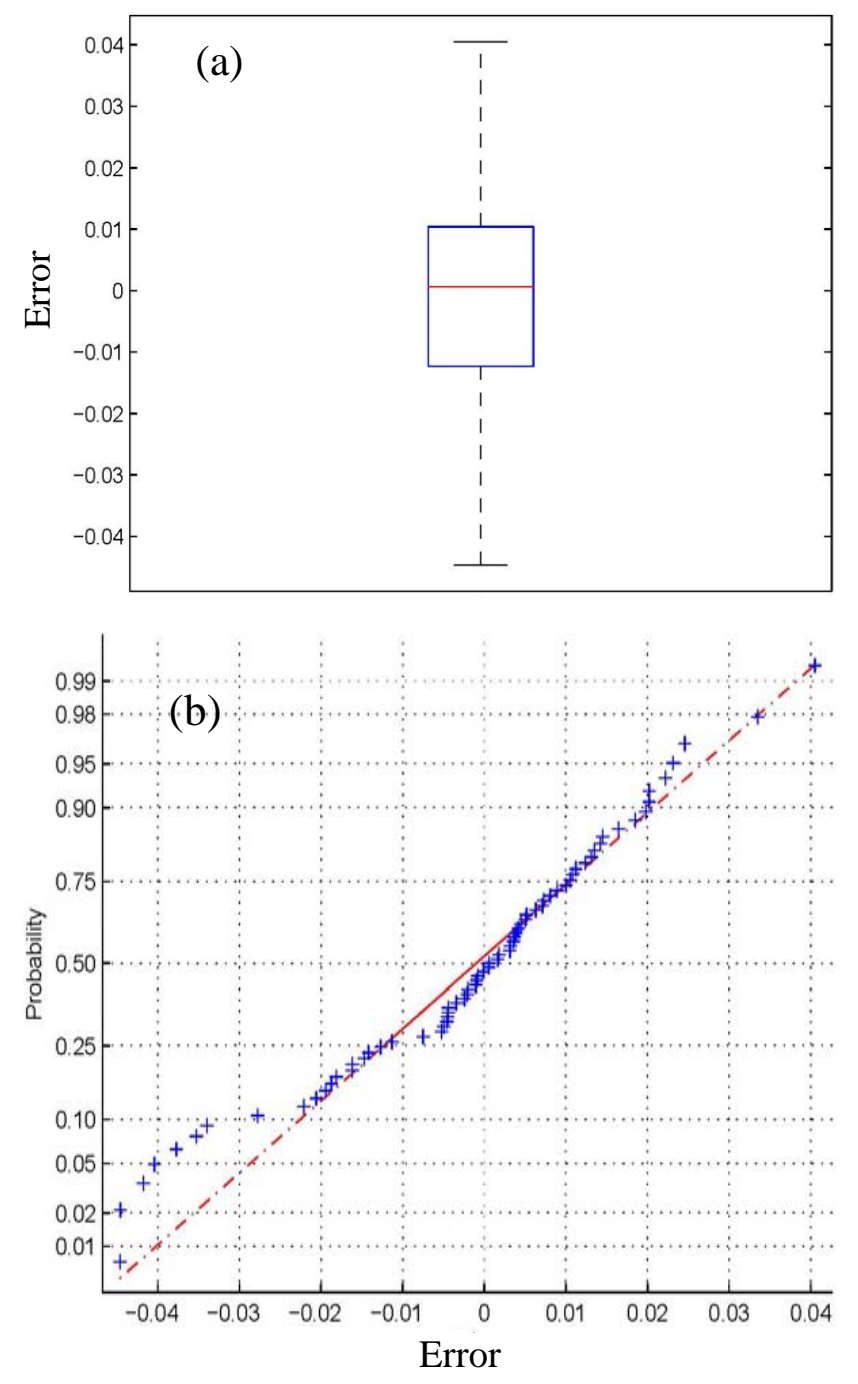

Fig. 4. (a) Statistics of error estimate for the data shown in Fig. 3. The median, 25th and 75th percentiles and the range are shown with outliers excluded. (b) Estimation error normality, a straight line indicates a normal distribution.

with 2009 data. This also confirms the quality of the constructed estimate $r$ for describing the dry and wet ratio for both years.

Especially, we observe that Fig. 5 shows an even better clustering around $1: 1$ line than Fig. 3, which indicates that our method performs better on the 2010 validating data than on the 2009 data. A close look at the data shows that 2010 data contain some higher values around $0.06 \mathrm{ng} \mathrm{m}^{-3}$, and our method estimates these values are close to reality. This confirms our observation from Fig. 4 that for large concentration values, the underlying normality assumption of our statistical model is satisfied well. Hence our method is able to generate a highly accurate estimate in this region. The 2010 data also do not have a large number of concentration values in the region from 0.02 to $0.04 \mathrm{ng} \mathrm{m}^{-3}$, which constitute the majority 


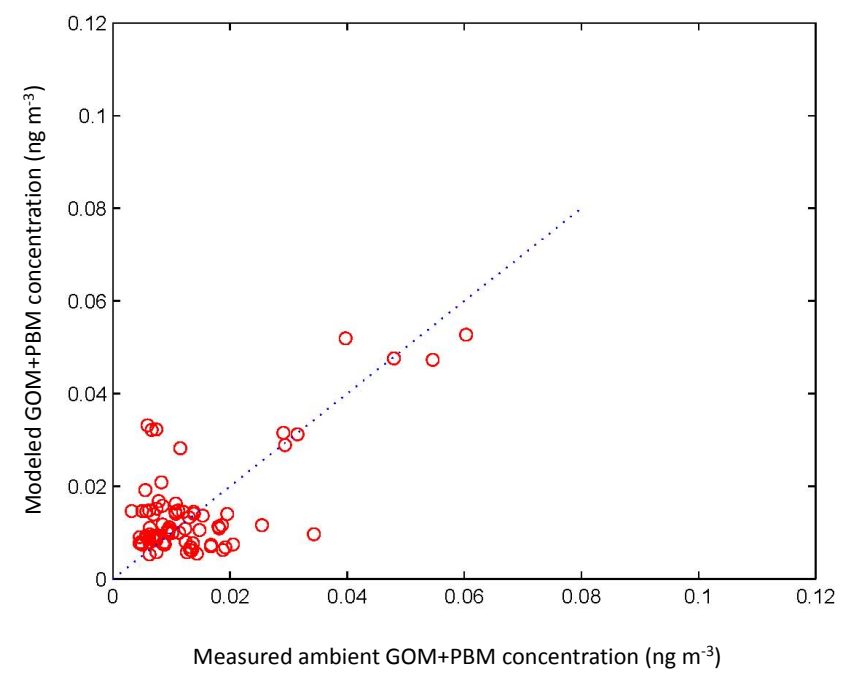

Fig. 5. Scatter plot of modelled and measured ambient GOM + PBM for 2010 validation data.

of variations in the 2009 data. The combined effect of the data pattern, and the robustness of our statistical method for estimating large concentrations yields the better clustering around $1: 1$ effect in Fig. 5.

\section{Conclusions and recommendations}

We proposed a new approach to estimate ambient oxidized mercury concentration by using mercury wet deposition information. Several superstations were selected for this study to establish the regression model. We found that $\mathrm{GOM}+\mathrm{PBM}$ concentration $c$ is not linear to the wet deposition $w$ and the precipitation $P$. Instead, a highly nonlinear relationship appears. For example, a higher value of wet deposition $w$ typically associates with a moderate increase of concentration. With beta distribution fitting experiment, and using 2009 data, we fit $\alpha_{r}$ and $\beta_{r}$ and get the mean, median, mode, std, skewness of the fitted beta distribution. Comparing the normalized histogram and the fitted density function, the empirical and fitted beta distributions of the ratio $r$ show a very close fit. The fitting model is further validated using data at a different number of sites and in a different year. The estimated monthly data of the ambient oxidized $\mathrm{Hg}$ agree reasonably well compared with monitored data.

There are areas to improve the statistical model. For example, we observe that wet deposition due to the washout effect is less evident in the later period of a precipitation event. Hence the monthly result of this section could not reflect the temporal changes in wet and dry ambient concentration during a given precipitation period. Furthermore, the parameter $\alpha_{r}$ and $\beta_{r}$ and the definition of ratio $r$ are not optimized. $\alpha_{r}$ and $\beta_{r}$ were obtained by the method of moments in the current study, which could be improved by the maximum likelihood method. The definition of ratio $r$ is experimental, which
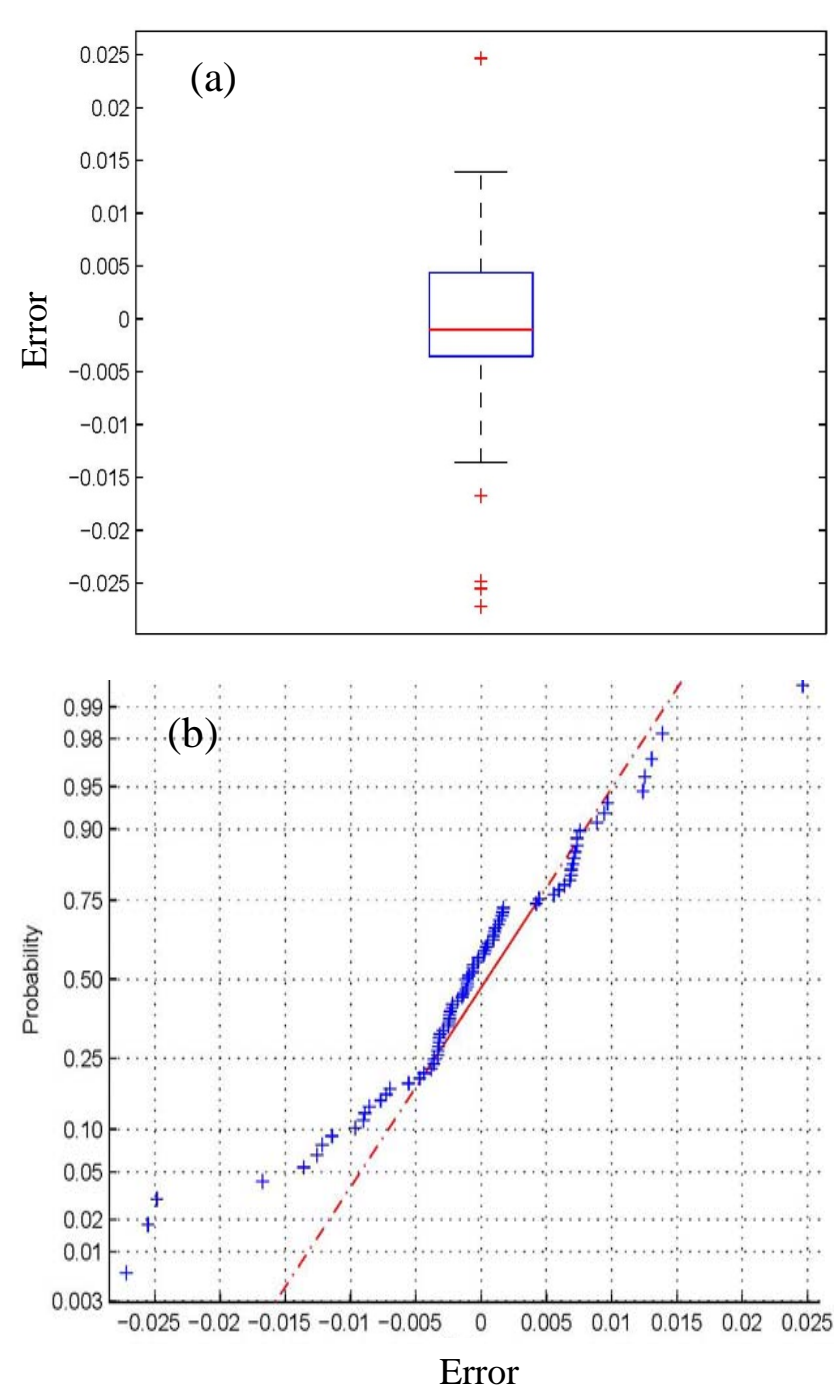

Fig. 6. Same as in Fig. 4 except for 2010 data.

could also be optimized by more observation data and a more advanced model of nonlinear optimization with constraints.

The estimated ambient concentration is for the total of GOM and PBM and can be further partitioned into GOM and PBM (e.g. using the method described in Amos et al., 2012). We did not iterate this method here because we think there is room to improve the method to include coarse PBM, which contributes to wet deposition. Also, more knowledge of the partitioning between GOM and PBM is needed to improve the method. We are investigating these areas and will present the results separately. The method developed in the present study, after further improvements and validation, is expected to be useful in many applications (e.g. to estimate monthly ambient concentration on continental scales for dry deposition mapping purposes or to compare with mercury transport model results). 


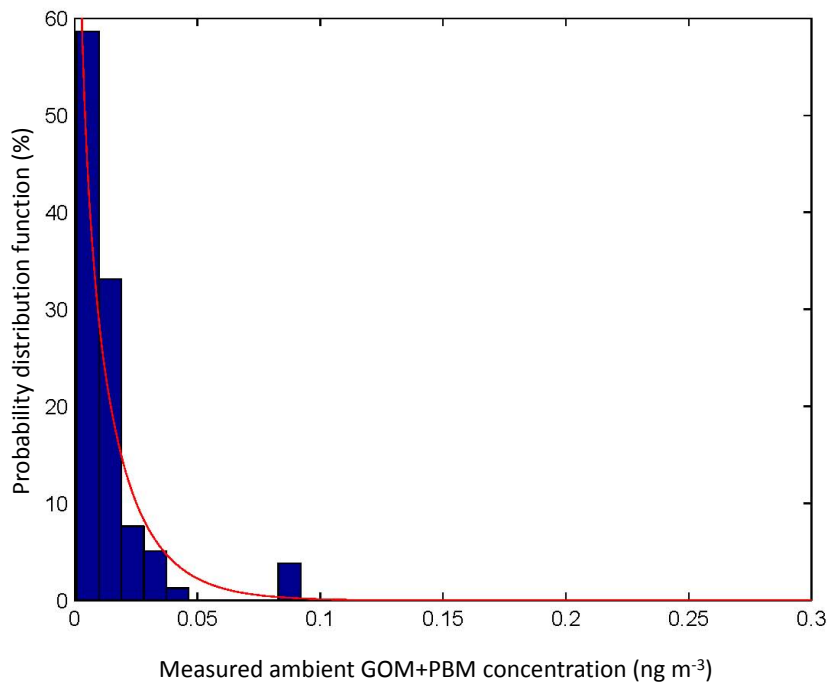

Fig. 7. Same as in Fig. 1 except for 2010 data at seven sites.

\section{Appendix A}

Formulation of wet deposition change

$K^{*}=K_{298}^{*} \exp \left(-\frac{\Delta H_{298}^{O}}{R}\left(\frac{1}{T}-\frac{1}{T_{0}}\right)\right)$

$F=f \frac{K^{*} L_{p} R T}{1+K^{*} L_{p} R T}$

$L_{p}=\frac{P \Delta t}{f \Delta Z}$

$F_{\max }=f\left[1-\exp \left(-k^{\prime} \frac{P}{f} \Delta t\right)\right]$

$\Delta m=F m+\left(1-\frac{F}{f}\right) l$

$\Delta m=-F_{\max } m+\left(1-F_{\max }^{\prime}\right) l$, when $F>F_{\max }$

Equation (A1) follows Liu et al. (2001). Equations (A2) and (A6) follow the Appendix in Amos et al. (2012), where we let $f=1, \Delta t=1$, and $\Delta Z=1$ since our data set contains uniformly weekly data with the rain gauge as the grid box. Consequently, we assume the coefficient $F_{\max }^{\prime}=\frac{1}{2}$ in Eq. (A6). We note that the change of wet deposit $\Delta w$ is complementary to the change of soluble gas $\Delta m$. The sum of $\Delta w+\Delta m$ equals $m_{T}$, which is exogenous. Hence the mass balance equations in use in our model are

$$
\begin{gathered}
\Delta w=F m+F l, \\
\Delta w=F_{\max } m+F_{\max }^{\prime} 1
\end{gathered}
$$

Since $F, F_{\max }$ and $F_{\max }^{\prime}$ are functions of temperature in kelvin and precipitation, we let

$F_{T P}=\left\{\begin{array}{ll}F & F \ll F_{\max } \\ F_{\max } & \text { otherwise }\end{array}, \quad F_{T P}^{\prime}= \begin{cases}F & F \ll F_{\max } \\ F_{\max }^{\prime} & \text { otherwise. }\end{cases}\right.$

\begin{tabular}{|c|c|}
\hline$\Delta H_{298}^{O}$ & $\begin{array}{l}\text { enthalpy change of formation for } \mathrm{Hg}^{0} \text {, equals } \\
-90.83 \text {; }\end{array}$ \\
\hline$R$ & universal gas $\quad$ constant, equals \\
\hline$K^{*}$ & $\begin{array}{l}\text { Henry's law constant (water solution) for mercury, } \\
\text { equals } 0.142344424 \text {, follows Eq. (A1); see Eq. (8) } \\
\text { in Liu et al. (2001); }\end{array}$ \\
\hline$P$ & precipitation $\left(\mathrm{cm}^{3}\right.$ water $\mathrm{cm}^{-2}$ surface $\left.\mathrm{s}^{-1}\right)$; \\
\hline$T$ & Temperature in kelvin; \\
\hline$f$ & $\begin{array}{l}\text { areal fraction of the grid box experiencing precipita- } \\
\text { tion, equals } 1 \text {; }\end{array}$ \\
\hline$L_{p}$ & $\begin{array}{l}\text { the time-integrated rain water content in the precipi- } \\
\text { tating fraction of the grid box; }\end{array}$ \\
\hline$\Delta t$ & time step, equals 1 \\
\hline$\Delta Z$ & the grid box thickness $(\mathrm{cm})$, equals 1 \\
\hline$k^{\prime}$ & $\begin{array}{l}\text { washout rate constant, equals } 1 \mathrm{~cm}^{-1} \text {; see Table } 2 \text { of } \\
\text { Levine and Schwartz (1982); }\end{array}$ \\
\hline$l$ & $\begin{array}{l}\text { the cumulative mass of gas scavenged via precipita- } \\
\text { tion from clouds; }\end{array}$ \\
\hline$\Delta m$ & the change in mass of the soluble gas due to washout; \\
\hline$\Delta w$ & $\begin{array}{l}\text { the change in wet deposition in the rain gauge due to } \\
\text { washout; }\end{array}$ \\
\hline$F_{\max }$ & $\begin{array}{l}\text { the maximal value of } F \text { based on detailed mass trans- } \\
\text { fer calculation by Levine and Schwartz (1982); }\end{array}$ \\
\hline$F_{\text {max }}^{\prime}$ & $\begin{array}{l}\text { the re-evaporation and partial shrinkage fraction con- } \\
\text { stant based on Liu et al. (2001). }\end{array}$ \\
\hline$F_{T P}$ & $\begin{array}{l}\text { fraction of gas scavenged from air as a function of } T \\
\text { and } P \text {; }\end{array}$ \\
\hline$F_{T P}^{\prime}$ & $\begin{array}{l}\text { fraction of gas scavenged from exogenous cloud as a } \\
\text { function of } T \text { and } P \text {; }\end{array}$ \\
\hline$s, t$ & index of sites and time stamps \\
\hline
\end{tabular}

Table A1. List of nomenclature.

Hence the Eqs. (17) and (18) are unified into

$\Delta w=F_{T P} m+F_{T P}^{\prime} l$.

Acknowledgements. We appreciate all the people who have contributed to the data collection and quality control for the AMNet and MDN data sets that are used in the present study.

Edited by: J. H. Seinfeld

\section{References}

Amos, H. M., Jacob, D. J., Holmes, C. D., Fisher, J. A., Wang, Q., Yantosca, R. M., Corbitt, E. S., Galarneau, E., Rutter, A. P., Gustin, M. S., Steffen, A., Schauer, J. J., Graydon, J. A., St Louis, V. L., Talbot, R. W., Edgerton, E. S., Zhang, Y., and Sunderland, E. M.: Gas-particle partitioning of atmospheric $\mathrm{Hg}(\mathrm{II})$ and its effect on global mercury deposition, Atmos. Chem. Phys., 12, 591-603, doi:10.5194/acp-12-591-2012, 2012. 
Baker, K. R. and Bash, J. O.: Regional scale photochemical model evaluation of total mercury wet deposition and speciated ambient mercury, Atmos. Environ., 49, 151-162, 2012.

Cheng, I., Zhang, L., Blanchard, P., Graydon, J. A., and St Louis, V. L.: Source-receptor relationships for speciated atmospheric mercury at the remote Experimental Lakes Area, northwestern Ontario, Canada, Atmos. Chem. Phys., 12, 1903-1922, doi:10.5194/acp-12-1903-2012, 2012.

Cheng, I., Zhang, L., Blanchard, P., Dalziel, J., Tordon, R., Huang, J., and Holsen, T. M.: Comparing mercury sources and atmospheric mercury processes at a coastal and inland site, J. Geophys. Res.-Atmos., 118, 2434-2443, doi:10.1002/jgrd.50169, 2013.

Choi, H.-D., Holsen, T. M., and Hopke, P. K.: Atmospheric Mercury $(\mathrm{Hg})$ in the Adirondacks: Concentrations and Sources, Environ. Sci. Technol., 42, 5644-5653, 2008.

Engle, M. A., Tate, M. T., Krabbenhoft, D. P., Kolker, A., O1son, M. L., Edgerton, E. S., DeWild, J. F., and McPherson, A. K.: Characterization and cycling of atmospheric mercury along the central US Gulf Coast, Appl. Geochem., 23, 419-437, doi:10.1016/j.apgeochem.2007.12.024, 2008.

Engle, M. A., Tate, M. T., Krabbenhoft, D. P., Schauer, J. J., Kolker, A., Shanley, J. B., and Bothner, M. H.: Comparison of atmospheric mercury speciation and deposition at nine sites across central and eastern North America. J. Geophys. Res.-Atmos., 115, D18306, doi:10.1029/2010JD014064, 2010.

Feddersen, D. M., Talbot, R., Mao, H., and Sive, B. C.: Size distribution of particulate mercury in marine and coastal atmospheres, Atmos. Chem. Phys., 12, 10899-10909, doi:10.5194/acp-1210899-2012, 2012.

Gay, D. A., Schmeltz, D., Prestbo, E., Olson, M., Sharac, T., and Tordon, R.: The Atmospheric Mercury Network: measurement and initial examination of an ongoing atmospheric mercury record across North America, Atmos. Chem. Phys. Discuss., 13, 10521-10546, doi:10.5194/acpd-13-10521-2013, 2013.

Gustin, M. S. and Jaffe, D.: Reducing the Uncertainty in Measurement and Understanding of Mercury in the Atmosphere, Environ. Sci. Technol., 44, 2222-2227, 2010.

Huang, J., Choi, H.-D., Hopke, P. K., and Holsen, T. M.: Ambient Mercury Sources in Rochester, NY: Results from Principle Components Analysis (PCA) of Mercury Monitoring Network Data, Environ. Sci. Technol., 44, 8441-8445, 2010.

Hynes, A., Donohoue, D., Goodsite, M., Hedgecock, I., Pirrone, N., and Mason, R.: Our current understanding of major chemical and physical processes affecting mercury dynamics in the atmosphere and at air-water/terrestrial interfaces. Mercury Fate and Transport in the Global Atmosphere, edited by: Pirrone, N. and Mason, R. P., chap. 14, Springer, 322-344, 2009.

Levine, S. Z. and Schwartz, S. E.: In-cloud and below-cloud scavenging of nitric acid vapor, Atmos. Environ., 16, 1725-1734, 1982.
Liu, H. Y., Jacob, D. J., Bey, I., and Yantosca, R. M.: Constraints from $\mathrm{Pb}-210$ and $\mathrm{Be}-7$ on wet deposition and transport in a global three-dimensional chemical tracer model driven by assimilated meteorological fields, J. Geophys. Res., 106, 12109 12128, doi:10.1029/2000jd900839, 2001.

Lombard, M. A. S., Bryce, J. G., Mao, H., and Talbot, R.: Mercury deposition in Southern New Hampshire, 2006-2009, Atmos. Chem. Phys., 11, 7657-7668, doi:10.5194/acp-11-76572011, 2011.

Lynam, M. M. and Keeler, G. J.: Source-receptor relationships for atmospheric mercury in urban Detroit, Michigan, Atmos. Environ., 40, 3144-3155, 2006.

Rutter, A. P., Snyder, D. C., Stone, E. A., Schauer, J. J., GonzalezAbraham, R., Molina, L. T., Márquez, C., Cárdenas, B., and de Foy, B.: In situ measurements of speciated atmospheric mercury and the identification of source regions in the Mexico City Metropolitan Area, Atmos. Chem. Phys., 9, 207-220, doi:10.5194/acp-9-207-2009, 2009.

Sprovieri, F., Hedgecock, I. M., and Pirrone, N.: An investigation of the origins of reactive gaseous mercury in the Mediterranean marine boundary layer, Atmos. Chem. Phys., 10, 3985-3997, doi:10.5194/acp-10-3985-2010, 2010.

Steffen, A., Douglas, T., Amyot, M., Ariya, P., Aspmo, K., Berg, T., Bottenheim, J., Brooks, S., Cobbett, F., Dastoor, A., Dommergue, A., Ebinghaus, R., Ferrari, C., Gardfeldt, K., Goodsite, M. E., Lean, D., Poulain, A. J., Scherz, C., Skov, H., Sommar, J., and Temme, C.: A synthesis of atmospheric mercury depletion event chemistry in the atmosphere and snow, Atmos. Chem. Phys., 8, 1445-1482, doi:10.5194/acp-8-1445-2008, 2008.

Swartzendruber, P. C., Jaffe, D. A., Prestbo, E. M., Weiss-Penzias, P., Selin, N. E., Park, R., Jacob, D. J., Strode, S., and Jaeglé, L.: Observations of reactive gaseous mercury in the free troposphere at the Mount Bachelor Observatory, J. Geophys. Res.-Atmos., 111, D24301, doi:10.1029/2006JD007415, 2006.

Weiss-Penzias, P., Gustin, M. S., and Lyman, S. N.: Observations of speciated atmospheric mercury at three sites in Nevada: Evidence for a free tropospheric source of reactive gaseous mercury. J. Geophys. Res.-Atmos., 114, D14302, doi:10.1029/2008JD011607, 2009.

Zhang, L., Blanchard, P., Johnson, D., Dastoor, A., Ryzhkov, A., Lin, C.-J., Vijayaraghavan, K., Gay, D., Holsen, T. M., Huang, J., Graydon, J. A., St. Louis, V. L., Castro, M. S., Miller, E. K., Marsik, F., Lu, J., Poissant, L., Pilote, M., and Zhang, K. M.: Assessment of modeled mercury deposition over the Great Lakes region, Environ. Pollut., 161, 272-283, 2012a.

Zhang, L., Blanchard, P., Gay, D. A., Prestbo, E. M., Risch, M. R., Johnson, D., Narayan, J., Zsolway, R., Holsen, T. M., Miller, E. K., Castro, M. S., Graydon, J. A., Louis, V. L. St., and Dalziel, J.: Estimation of speciated and total mercury dry deposition at monitoring locations in eastern and central North America, Atmos. Chem. Phys., 12, 4327-4340, doi:10.5194/acp-12-43272012, 2012b. 